Jessica Gill, RN, PhD

Kian Merchant-Borna, $\mathrm{MPH}$

Andreas Jeromin, $\mathrm{PhD}$

Whitney Livingston, BA

Jeffrey Bazarian, MD, $\mathrm{MPH}$

Correspondence to

Dr. Gill:

gillj@mail.nih.gov

\title{
Acute plasma tau relates to prolonged return to play after concussion OPEN
}

\section{ABSTRACT}

Objective: To determine whether tau changes after sport-related concussion (SRC) relate to return to play (RTP).

Methods: Collegiate athletes underwent preseason plasma sampling and cognitive testing and were followed. After a SRC $(n=46)$, athletes and controls $(n=37)$ had sampling at 6 hours, and at 24 hours, 72 hours, and 7 days after SRC. A sample of 21 nonathlete controls were compared at baseline. SRC athletes were grouped by long ( $>10$ days, $n=23$ ) and short ( $\leq 10$ days, $n=18)$ RTP. Total tau was measured using an ultrasensitive immunoassay.

Results: Both SRC and athlete controls had significantly higher mean tau at baseline compared to nonathlete healthy controls $\left(F_{101,3}=19.644, p<0.01\right)$. Compared to SRC athletes with short RTP, those with long RTP had higher tau concentrations overall, after controlling for sex $\left(F_{39,1}=\right.$ 3.59, $p=0.022)$, compared to long RTP athletes, at $6(p<0.01), 24(p<0.01)$, and 72 hours ( $p$ $=0.02$ ). Receiver operator characteristic analyses showed that higher plasma tau 6 hours postSRC was a significant predictor of RTP $>10$ days (area under the curve $0.81 ; 95 \%$ confidence interval 0.62-0.97, $p=0.01$ ).

Conclusions: Elevated plasma tau concentration within 6 hours following a SRC was related to having a prolonged RTP, suggesting that tau levels may help inform RTP. Neurology ${ }^{\circledR}$ 2017;88:595-602

\section{GLOSSARY}

ANOVA $=$ analysis of variance; $\mathbf{A U C}=$ area under the curve; $\mathbf{B E S S}=$ Balance Error Scoring System; $\mathbf{C l}=$ confidence interval; CTE = chronic traumatic encephalopathy; ImPACT = Immediate Postconcussion Assessment and Cognitive Testing; $\mathbf{m T B I}=$ mild traumatic brain injury; NCAA = National Collegiate Athletic Association; RTP = return to play; $\mathbf{S R C}=$ sports-related concussions; $\mathbf{T B I}=$ traumatic brain injury.

Despite the 3.8 million sports-related concussions (SRC) that occur annually in the United States, there are currently no prognostic biomarkers to predict recovery and an athlete's readiness to return to play (RTP). ${ }^{1}$ Concussions have complex and variable neuronal pathophysiology, ${ }^{2}$ resulting in symptoms of postconcussive syndrome and cognitive deficits ${ }^{3}$ that typically resolve within 10 days in approximately half of concussed collegiate athletes ${ }^{4}$; yet in a subset of athletes these symptoms and deficits are chronic. ${ }^{2}$ An objective predictor of recovery time in the acute aftermath of SRC would provide an unbiased tool that could be used to assist in determining an athlete's readiness of RTP, preventing premature RTP. ${ }^{5}$

Determining RTP is essential as athletes who return to play prior to full neuronal recovery are at high risk for long-term symptoms and deficits if they sustain a subsequent concussion. ${ }^{6}$ Chronic traumatic encephalopathy (CTE) is linked to playing contact sports, which often includes repetitive head trauma, with the hallmark pathologic feature being hyperphosphorylated tau and the formation of perivascular neurofibrillary tangles. ${ }^{7}$ Tau is linked to axonal damage following traumatic brain injury, ${ }^{8-11}$ and to SRCs, ${ }^{12}$ with elevations being predictive of a RTP greater than 10 days in professional ice hockey players. ${ }^{13}$ To investigate the relationship

From the National Institute of Nursing Research (J.G., W.L.), NIH, Bethesda, MD; Department of Emergency Medicine (K.M.-B., J.B.), University of Rochester School of Medicine and Dentistry, Rochester, NY; and Quanterix Corporation (A.J.), Lexington, MA.

Go to Neurology.org for full disclosures. Funding information and disclosures deemed relevant by the authors, if any, are provided at the end of the article. The Article Processing Charge was paid by the authors.

This is an open access article distributed under the terms of the Creative Commons Attribution-NonCommercial-NoDerivatives License 4.0 (CC BY-NC-ND), which permits downloading and sharing the work provided it is properly cited. The work cannot be changed in any way or used commercially without permission from the journal. 
in a younger cohort of both sexes, we evaluated changes in tau following concussion compared to preseason, and also compared tau changes following SRC to both an athletic control group and healthy nonathletic controls. We hypothesized that acute tau increases would result in a longer duration of RTP.

METHODS Participants. Between 2009 and 2014, 632 National Collegiate Athletic Association (NCAA) division I and III collegiate contact sport athletes underwent plasma sampling and cognitive testing prior to the sports season, and were followed prospectively for a diagnosis of SRC. SRC was defined as an injury witnessed by an on-field certified athletic trainer and meeting the definition of concussion as defined by the Sport Concussion Assessment Tool 2. ${ }^{14}$ This tool provides a structured framework for evaluating 22 postconcussive symptoms as well as orientation, memory, recall, balance, and gait. In athletes with a diagnosed SRC, plasma samples were obtained within 6 hours of injury, and then at 2, 3, and 7 days postinjury. Plasma sampling was also performed in 2 control groups; nonconcussed athlete controls had blood draws at the same time points as SRC athletes and healthy, nonathlete controls at an unrelated time point. Concussions occurred between 19 and 218 days following baseline assessments, with a mean of 92.3 days. Then athletes and controls had repeat testing using Balance Error Scoring System (BESS) and Immediate Postconcussion Assessment and Cognitive Testing (ImPACT) 7 days following the date of the concussion. In this study, controls were oversampled when it was feasible. At the beginning of the season, athletes were matched to controls on a 1:1 basis, and when possible on a 1:2 basis to assure that enough controls were obtained.

Healthy controls were recruited through a protocol to obtain serum samples on participants without a history of head injuries. Head injury history was determined by the Ohio State Traumatic Brain Injury Identification Method, which is both valid and reliable in detecting lifetime histories of traumatic brain injuries (TBIs). ${ }^{15}$ Controls were selected from a pool of participants and matched to SRC athletes in sex and age.

Standard protocol approvals, registrations, and patient consents. The institutional review board at the University of Rochester and Rochester Institute of Technology approved this study with human participants, and all participants provided written informed consent prior to beginning the study (protocols: 24457 and 22971).

Return to play. RTP for each athlete was determined by the athletic trainers or team physicians at their respective universities. Both universities followed the NCAA RTP guidelines, which recommend that athletes be asymptomatic at rest and with each step of the RTP progression before returning to their sport. In addition, cognition and postural stability should be at preinjury levels.

Clinical outcome after SRC. Clinical outcome after SRC was determined by changes in cognitive performance, postconcussive symptoms, and postural stability from baseline to 7 days following a SRC. Determination of cognition and postural stability was made using ImPACT and BESS, respectively. ImPACT is a proprietary computer program that measures verbal memory, visual memory, reaction time, and visuomotor speed, ${ }^{16}$ and a postconcussive symptom inventory. ${ }^{17}$ Athletes were instructed to complete the ImPACT test on a desktop computer in a quiet room.
Each BESS assessment consists of 3 stances (double, single, and tandem) in 2 conditions (firm surface and foam surface), all performed with the eyes closed for 20 seconds per stance. A trained member of the study staff followed the standard procedures for BESS administration. The BESS score is calculated by adding 1 error point for each performance error, with a maximum of 10 errors per stance. ${ }^{18}$

Blood collection and assays. Venous blood was collected in a nonfasting state in lavender top EDTA tubes and placed on ice until processed. All blood was centrifuged less than 60 minutes from the time of blood draw, at $4^{\circ} \mathrm{C}$ at 3,000 rpm for 10 minutes, and then plasma was isolated and samples were stored in a $-80^{\circ} \mathrm{C}$ freezer until batch assayed by a blinded technician.

Biochemical procedures. Tau concentrations in plasma samples were measured by immunoassay using digital array technology, which uses a single molecule enzyme-linked immunoarray (Simoa) method described in detail in Rissin et al. ${ }^{19}$ The Simoa human total tau assay measures total tau concentrations by using a combination of monoclonal antibodies. The capture antibody reacts with a linear epitope in the midregion of all tau isoforms, while the detection antibody reacts with a linear epitope in the $\mathrm{N}$-terminus of total tau. The limit of detection for the assay is $0.012 \mathrm{pg} / \mathrm{mL}$. The intra-assay coefficient was $8.25 \%$.

Statistical analysis methods. Statistical analyses were conducted with Statistical Package for the Social Sciences (SPSS version 22; IBM Corporation, Armonk, NY), and figures were developed using GraphPad Prism (v. 6.02) (Graph Pad Software, San Diego, CA). Demographics were compared among the 3 groups using an analysis of variance (ANOVA) to compare age and a $\chi^{2}$ test to compare the groups on race, ethnicity, and sex. Among the athlete groups, $\chi^{2}$ testing was used to compare the 2 groups in the type of sport played and history of prior concussion. Median changes in the ImPACT and the BESS were compared using an unpaired 2-sample $t$ test.

Tau concentrations were compared among the 3 groups (SRC athletes, nonconcussed athlete controls, and healthy nonathlete controls) using an ANOVA, with a Bonferroni post hoc test at all 5 time points. To compare changes within the 2 athlete groups (SRC and athlete controls), a repeated-measures ANOVA, with Bonferroni post hoc test, were performed to determine whether tau concentrations differed, and at which time points differences were significant between the groups. Mean change in tau from baseline was compared for the 4 post-SRC time points using ANOVA. Area under the curve (AUC) using a receiver operating characteristic analysis was also used to determine the ability of tau at each time point to predict group membership.

For our last comparison, we determined differences within the SRC group based on the RTP duration. SRC athletes were dichotomized into long ( $\geq 10$ days) and short ( $<10$ days) RTP groups, and mean tau concentrations were compared at each of the 5 time points using a repeated-measures ANOVA while controlling for sex as a covariate. An AUC was also used to determine whether tau at any of the 5 time points predicted long RTP.

RESULTS Participants and blood samples. During the study period, 46 collegiate contact sport athletes were diagnosed with an SRC. Thirty-seven athletes who also underwent blood sampling and cognitive testing prior to the sports season (baseline), but did not have a SRC, served as teammate controls. Teammate controls and SRC athletes did not significantly differ in sport played, history of SRC, 
Table 1 Characteristics of study participants

\begin{tabular}{|c|c|c|c|c|}
\hline Characteristics & $\begin{array}{l}\text { Control athletes } \\
(\mathrm{n}=37)\end{array}$ & $\begin{array}{l}\text { SRC athletes } \\
(n=43)\end{array}$ & $\begin{array}{l}\text { Nonathlete } \\
\text { controls }(n=21)\end{array}$ & p Value \\
\hline Female sex, $n(\%)$ & $22(59.5)$ & $20(46.5)$ & $15(71.4)$ & 0.154 \\
\hline Age, y, mean (SD) & $18.7(0.67)$ & $19.1(1.18)$ & $19.2(0.98)$ & 0.13 \\
\hline Race, n (\%) & & & & 0.760 \\
\hline Caucasian & 25 (67.6) & $32(74.4)$ & $11(52.4)$ & \\
\hline Black/African American & $1(2.7)$ & $1(2.3)$ & 7 (33.3) & \\
\hline Asian & $0(0.0)$ & $0(0.0)$ & $1(4.8)$ & \\
\hline More than one race & $1(2.7)$ & $2(4.7)$ & $0(0.0)$ & \\
\hline Unknown/not reported & $10(27.0)$ & 8 (18.6) & $2(9.5)$ & \\
\hline Ethnicity, n (\%) & & & & $<0.001$ \\
\hline Not Latino/Hispanic & $20(54.1)$ & 15 (34.9) & $18(85.7)$ & \\
\hline Latino/Hispanic & $0(0.0)$ & $1(2.3)$ & $3(14.3)$ & \\
\hline Unknown & $17(45.9)$ & $27(62.8)$ & $0(0.0)$ & \\
\hline Sport, n (\%) & & & & 0.136 \\
\hline Soccer & $21(56.8)$ & $17(39.5)$ & NA & \\
\hline Football & $11(29.7)$ & 15 (34.9) & NA & \\
\hline Basketball & 3 (8.1) & 5 (11.6) & NA & \\
\hline Hockey & $0(0.0)$ & 4 (9.3) & NA & \\
\hline Lacrosse & $2(5.4)$ & $2(4.7)$ & NA & \\
\hline Prior concussion, $\mathrm{n}(\%)$ & & & & 0.926 \\
\hline No/yes & $26 / 11$ & $31 / 12$ & NA & \\
\hline
\end{tabular}

Abbreviations: $\mathrm{NA}=$ not applicable; $\mathrm{SRC}=$ sports-related concussions.

or any other demographic feature (table 1). The second control group consisted of 21 healthy nonathletes who were selected due to similarities in age and sex with the SRC athletes. This healthy control group was similar to both athlete groups on

Table 2 Changes in cognition and postural stability from baseline to 7 days after sports-related concussions (SRC)

\begin{tabular}{|c|c|c|c|}
\hline & Control athletes & SRC athletes & $p$ Value \\
\hline \multicolumn{4}{|l|}{ Cognition, mean change (SD) } \\
\hline Verbal memory score & $-3.00(10.70)$ & $3.89(11.05)$ & 0.160 \\
\hline Visual memory score & $-0.50(10.29)$ & $0.08(11.76)$ & 0.890 \\
\hline Visual motor speed score & $-0.72(6.53)$ & $1.09(7.64)$ & 0.620 \\
\hline Reaction time seconds & $0.01(0.05)$ & $-0.02(0.11)$ & 0.592 \\
\hline Total symptom score & $0.33(1.37)$ & $-10.16(15.57)$ & 0.107 \\
\hline \multicolumn{4}{|c|}{$\begin{array}{l}\text { Postural stability, mean change } \\
\text { in number of errors (SD) }\end{array}$} \\
\hline Double leg, floor & $0.03(0.02)$ & $-0.04(0.19)$ & 0.445 \\
\hline Single leg, floor & $-0.50(1.86)$ & 0.07 (3.16) & 0.551 \\
\hline Tandem, floor & $-1.31(1.35)$ & $-0.50(2.35)$ & 0.203 \\
\hline Double leg, foam & $-0.06(0.44)$ & $-0.18(1.09)$ & 0.688 \\
\hline Single leg, foam & $-0.81(2.07)$ & $-0.54(2.97)$ & 0.772 \\
\hline Tandem, foam & $-2.38(3.03)$ & $-0.89(3.38)$ & 0.126 \\
\hline
\end{tabular}

demographic variables (table 1). Blood samples were collected within both athlete groups at baseline prior to the seasons $(n=80)$ and then at 6 hours $(n=67)$, 24 hours $(\mathrm{n}=61), 72$ hours $(\mathrm{n}=62)$, and 7 days after injury $(\mathrm{n}=60)$. Within the SRC group, RTP information was available for 41 athletes. The mean \pm SD RTP was $21.68 \pm 42.99$ days, with the longest RTP being 263 days and the shortest being 2 days. Five concussed athletes had a RTP of 30 days or more. Approximately 39\% had RTP duration shorter than 10 days. Within the SRC group, there were no differences in sport played, or history of concussion, based on long RTP $(n=23)$ vs short RTP $(\mathrm{n}=18)$. There were significant differences based on sex $\left(\chi^{2}=5.67, p=0.018\right)$. Women made up $61 \%$ of the long RTP group but only $28 \%$ of the short RTP group. We were unable to determine RTP in 5 of the concussed athletes due to missing data. These 5 missing athletes were similar to the 41 athletes in demographics, sports played, and BESS and ImPACT scores.

Clinical outcomes. SRC athletes did not significantly change in cognitive performance or postural stability from baseline to 7 days post-SRC compared to control athletes (table 2). Among SRC athletes with long RTP, there was no significant change in mean cognitive performance and balance from baseline to 7 days post-SRC compared to SRC athletes with short RTP.

Tau changes following SRC in concussed athletes and athlete controls. Both athlete groups had significantly higher mean tau concentrations compared to nonathlete controls $\left(F_{101,2}=19.644, p<0.01\right)$ at baseline as well as all other time points ( $p$ s $<0.01$ ) (figure $1 \mathrm{~A})$. We observed significant differences in the longitudinal pattern in tau among the SRC athletes compared to athlete controls $\left(F_{83,1}=8.74, p<0.01\right)$ (figure 1, A-C). SRC athletes had significantly lower mean total tau at 24 hours $(6.06$ vs $7.89 \mathrm{pg} / \mathrm{mL}, p=$ 0.030 ) and 72 hours (5.19 vs $6.94 \mathrm{pg} / \mathrm{mL}, p=$ $0.041)$ post-SRC compared to athlete controls (figure 1A).

Tau changes following SRC in those with short and long RTP. Compared to SRC athletes with short RTP, those with long RTP had higher tau concentrations overall, after controlling for sex $\left(F_{39,1}=3.59, p=\right.$ $0.022)$. These differences were statistically significant at 6 hours $(p<0.01), 24$ hours $(p<0.01)$, and 72 hours $(p=0.02)$ (figure $2, \mathrm{~A}-\mathrm{C}$ ), with higher tau concentrations at 6 hours $(10.98 \mathrm{vs} 7.02 \mathrm{pg} / \mathrm{mL}, p=$ 0.02 ), 24 hours (7.19 vs $4.08 \mathrm{pg} / \mathrm{mL}, p<0.01$ ), and 72 hours $(6.29$ vs $3.94 \mathrm{pg} / \mathrm{mL}, p<0.01)$. We also observed significant differences in mean change in tau from baseline, where athletes with long RTP exhibited a mean increase of $2.26 \mathrm{pg} / \mathrm{mL}$ 
Figure 1 Tau concentrations before and after sports-related concussion (SRC)
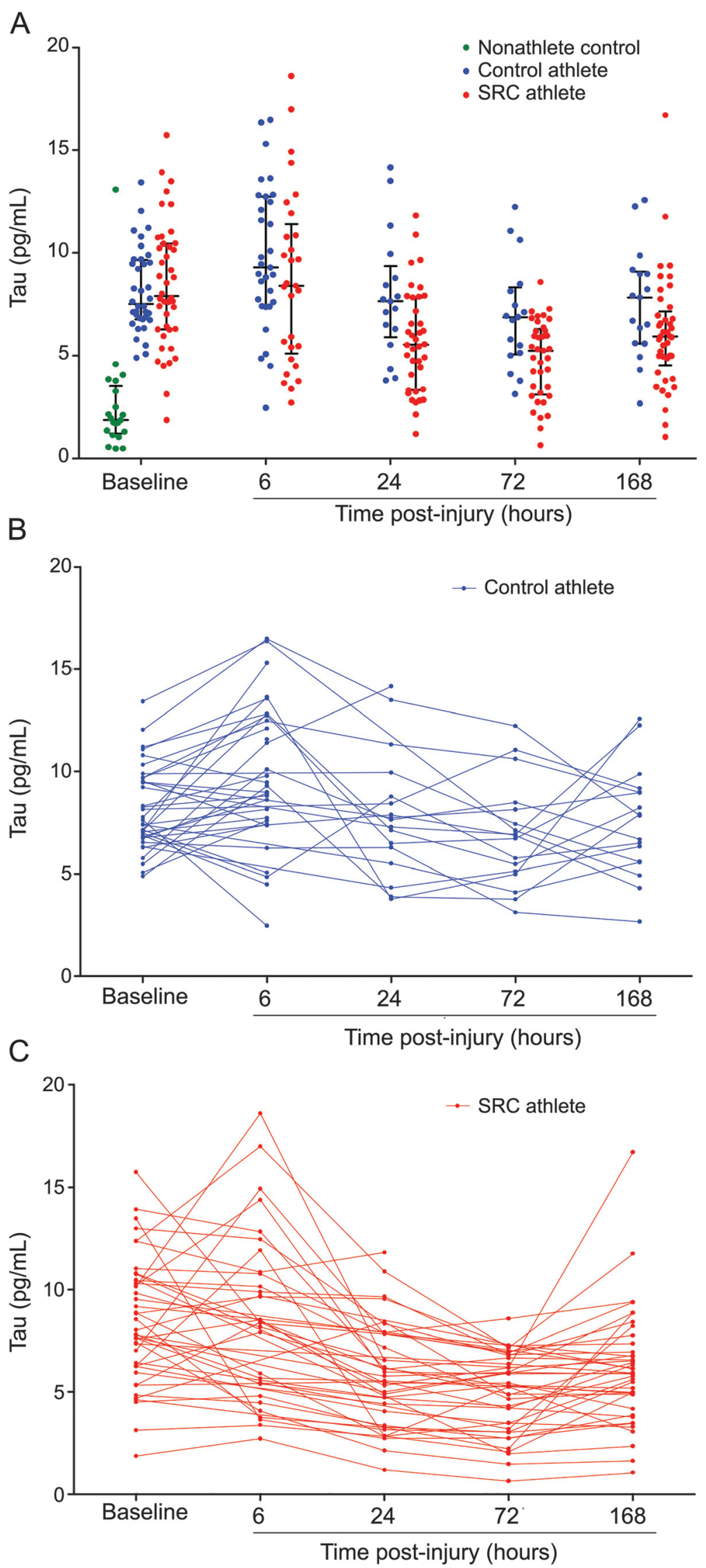

(A) Dots represent individual plasma tau concentrations among healthy, nonathlete controls (green), athlete controls (blue), and SRC athletes (red) at baseline (preinjury) and 4 time points
$\left(F_{33,1}=5.09, p<0.01\right)$ at 6 hours post-SRC compared to a mean reduction of $1.19 \mathrm{pg} / \mathrm{mL}$ in the short RTP group, while controlling for sex. AUC analyses revealed that higher total tau 6 hours post-SRC (AUC 0.81; 95\% confidence interval [CI] $0.62-0.97, p=0.01$ ) and the change in tau from baseline to 6 hours post-SRC (AUC 0.80; 95\% CI 0.57-0.94, $p=0.02$ ) were accurate predictors of RTP $\geq 10$ days (figure 3A). AUC analyses showed that higher total tau at 72 hours post-SRC (AUC $0.82 ; 95 \%$ CI $0.68-0.96, p<0.01)$ was a significant predictor of RTP $\geq 10$ days (figure $3 \mathrm{~B}$ ).

DISCUSSION We report that higher levels of plasma tau measured within 6 hours of SRC significantly relates to prolonged RTP. We also observed higher plasma tau concentrations at 24 and 72 hours postinjury in SRC athletes with prolonged RTP. By including a group of both male and female athletes, we also are able to show that these tau-related changes occur in both sexes, as well as within a variety of sports. Together these findings suggest that changes in total tau within 6 hours of a SRC may provide vital information about RTP decisions, and may serve to mitigate the negative consequences of returning to play prematurely.

Our findings expand on a previous report of higher tau at 1 and 12 hours following concussion compared to levels preseason in hockey players. ${ }^{12} \mathrm{We}$ add to this evidence by comparing SRC athletes to controls who continue participating in sports activity, showing that tau increases at the 6 hours time point following SRC, and that these levels decrease compared to athlete controls still engaged in sport play. We speculate that these findings may be due to the effects of physical exertion on tau. This finding is supported by a previous study that reports higher total tau in boxers 1-6 days following a bout, even in the absence of concussion, compared to healthy controls $^{12}$; however, it is not clear if this elevation is related to physical exertion or brain injury that did not result in injuries deemed to be concussion. An increase in total tau 1 hour after exercise is reported in a small group of athletes without concussion has been reported, ${ }^{20}$ suggesting that tau is elevated in athletes who have physical exertion, even in the absence of concussion. There is evidence that other neuropeptides also relate to brain injury. ${ }^{21-23}$ This increase

after SRC. Horizontal black lines denote the mean and interquartile range. (B) Blue lines represent participant-specific longitudinal changes in plasma tau concentrations from baseline to 4 time points after SRC among control athletes. (C) Red lines represent participant-specific longitudinal changes in plasma tau concentrations from baseline to 4 time points after SRC among athletes with an SRC. 
Figure 2 Tau concentrations among athletes with sports-related concussion (SRC) with short and long return to play (RTP)

A
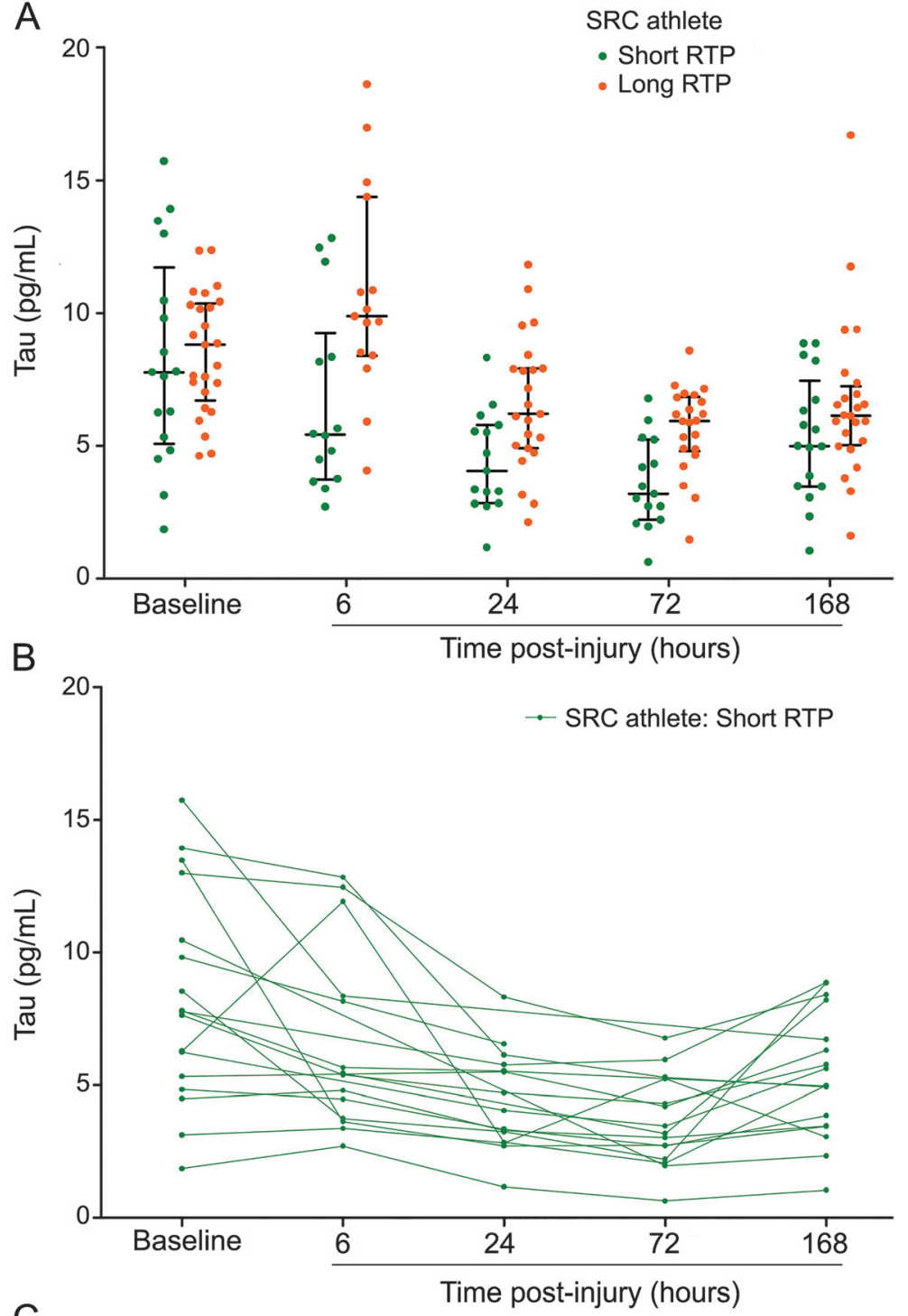

C

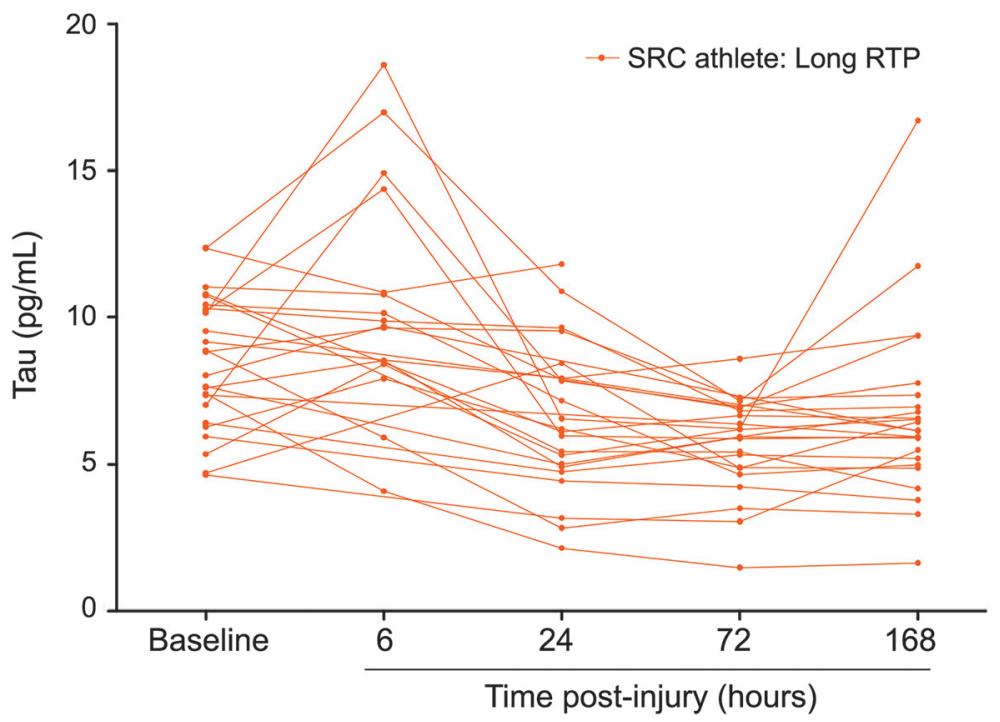

(A) Dots represent individual plasma tau concentrations among SRC athletes with short RTP (1-9 days, green) and long RTP ( $\geq 10$ days, red). Horizontal black lines denote mean and following physical exertion may result from increased neuronal activity induced by physical activity, ${ }^{24}$ most likely in conjunction with an increase in blood-brain barrier permeability that occurs in sports-related play, ${ }^{25}$ and these increases may relate to neuronal plasticity $^{23}$ and neurogenesis. ${ }^{26}$ These findings may also relate to sports-related play in the absence of concussions, including subconcussive blows during play that may result in subclinical neuronal injuries, as even brief hypoxia has been linked to higher tau levels. ${ }^{27}$ Additional studies are needed to understand the cumulative result of subconcussive blows on tau and how these subclinical injuries may then contribute to chronic neuronal pathology, such as CTE.

Our findings in the context of previous studies suggest that plasma tau not only increases with brain injury, but that it probably also goes up transiently with physical exertion. This also provides insights into why we observe higher mean tau concentrations at 6,48 , and 72 hours post-SRC in those with prolonged RTP, but not at the 7-day follow-up when most of the short RTP are re-engaged in sports activities. Finally, this finding highlights the need to consider the possible cofounding role of physical exertion on biomarkers of concussion in future studies, which should include an athletic control group that maintains engagement in sports-related physical activity.

Our findings indicate that higher tau at 6 hours predicts RTP, and builds off the observation that elevations of cleaved tau are predictive of a RTP greater than 10 days in professional ice hockey players. ${ }^{13}$ Within athletes, tau may indicate the severity of neuronal injury, which is difficult to determine with current assessments, ${ }^{28}$ as well as changes in cognitive performance and balance from baseline. ${ }^{29}$ It may be that tau concentrations combined with current RTP assessments could help protect athletes from the negative consequences of premature RTP. This is important as volitional underperformance is often observed in preseason neuropsychological testing, making it difficult for us and others to determine clinically

interquartile range. The 6-, 24-, and 72-hour time points were significantly different between low RTP and high RTP groups ( $p=0.007, p=0.006, p=0.001$, respectively). This figure indicates higher tau concentrations found at these 3 significant time points is related to high RTP, suggesting peripheral tau collection at these times may be important when determining a prognosis in SRC athletes. (B) Green lines represent participant-specific longitudinal changes in tau concentrations from baseline to 4 postinjury time points among SRC athletes with short RTP. (C) Orange lines represent participant-specific longitudinal changes in tau concentrations from baseline to 4 postinjury time points among SRC athletes with long RTP. 
A

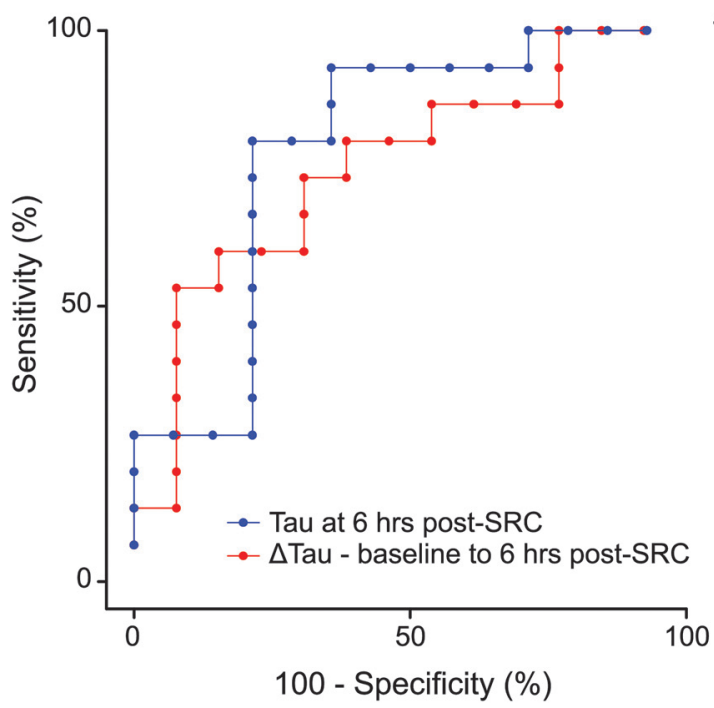

$\mathrm{B}$

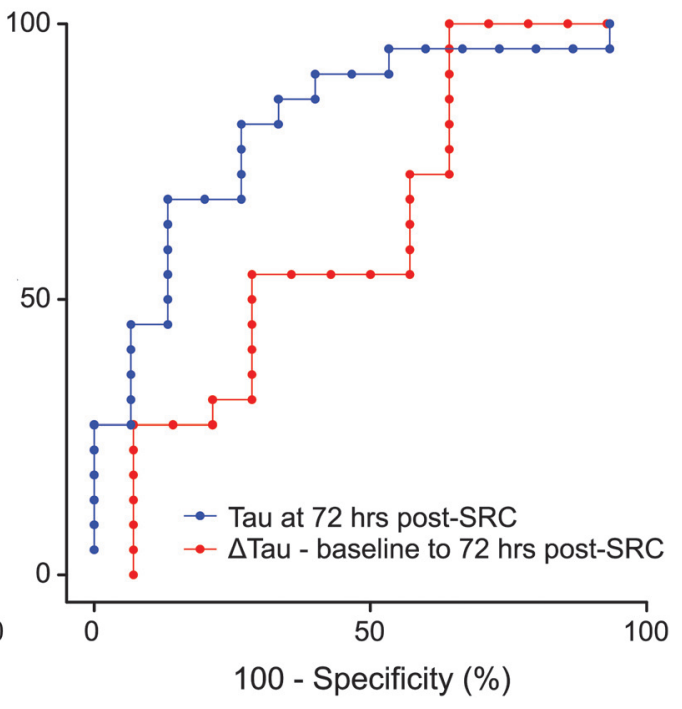

(A) Blue curve represents the receiver operating characteristic (ROC) of plasma tau measured 6 hours after SRC for predicting RTP. The area under the curve (AUC) was $0.81 ; 95 \%$ confidence interval (CI) $0.62-0.97, p=0.01$. The red curve represents the ROC of the participant-specific change in plasma tau from baseline to 6 hours after SRC for predicting RTP. AUC was $0.80 ; 95 \% \mathrm{CI} 0.57-0.94, p=0.02$. (B) Blue curve represents the ROC of plasma tau measured 72 hours after SRC for predicting RTP. The AUC was $0.82 ; 95 \% \mathrm{Cl} 0.68-0.96, \mathrm{p}<0.01$. The red curve represents the ROC of the participant-specific change in plasma tau from baseline to 72 hours after SRC for predicting RTP. AUC was $0.74 ; 95 \% \mathrm{Cl}$ $0.58-0.90, p=0.20$.

relevant changes in these measures. This may also relate to the protective role of cognitive reserve in these young college athletes. ${ }^{30}$ Identifying safe RTP is important as even transient tau elevations during the acute period following concussion may contribute to lasting neuronal impairment. This assertion is supported by a recent study that linked subacute tau elevations in concussed athletes to greater RTP. ${ }^{20}$

Identifying a biomarker to inform RTP may also protect athletes from the neuronal damage related to sustaining subsequent concussions prior to full recovery. Preclinical models link insufficient recovery time from a previous mild TBI (mTBI) to greater neuropathology following a subsequent mTBI, including white matter degradation,,$^{31,32}$ a pathology linked to neuronal tau accumulation. ${ }^{33}$ Repetitive mTBIs with insufficient recovery periods in preclinical models overlap with the pathology of CTE, including aggregation of phosphorylated tau. ${ }^{34}$ CTE is of great concern, as it results in nonreversible cognitive and behavioral symptoms and deficits in athletes with histories of multiple concussions. The hallmark neuronal pathology of CTE relates to tau accumulation in living athletes determined through imaging, ${ }^{35}$ which likely contributes to the formation of neurofibrillary tangles that include tau deposition in individuals who sustain multiple TBIs or concussions. ${ }^{6}$ Thus, even when concussed players are asymptomatic upon RTP, there may be residual effects that may lead to longterm consequences. ${ }^{6}$ Therefore, having a biomarker that could help in deterring safe RTP would be of great value in making these difficult decisions in athletes who are often not objectively impaired or subjectively reporting symptoms, but who are at risk for neuronal pathology resulting from subsequent concussions prior to full recovery.

This study is not without limitations, which includes a relatively small sample size within our subanalyses of long and short RTP; however, our use of paired baseline samples reduces the contribution of interindividual variation in tau protein concentrations. We also were limited by missing data on tau following concussion in some athletes, as well as peripheral blood not necessarily reflecting central changes. Although there were more women in the long RTP group compared to the short RTP group, we were able to statistically control for this difference in our models, and sex did not significantly contribute to these models. In future studies, we will also include additional proteomic biomarkers and other outcome measures, as it may be that tau can contribute to informing RTP decisions. Despite these limitations, we provide insights into the role of tau in SRC, including our finding that acute increases in tau 
concentrations within 6 hours of a SRC are predictive of RTP. Our results provide the necessary information to design future studies, which include the need to consider the effects of physical exertion on tau levels. Current limitations in determining RTP may be addressed by including an evaluation of acute elevations in tau following SRC to identify those athletes most at risk for poor recovery who require additional monitoring and clinical care to promote recovery.

\section{AUTHOR CONTRIBUTIONS}

Dr. Gill: performed data analyses and wrote the manuscript. K. MerchantBorna: organization of data and writing the manuscript. Dr. Jeromin: provided proteomic guidance and aided in study design. W. Livingston: creation of figures and tables and editing of manuscript. Dr. Bazarian: organization of research and study design and editing of manuscript.

\section{STUDY FUNDING}

This work was supported by funds from the NIH/NICHD (award no. K24HD064754) and the NIH, National Institute of Nursing Research Intramural Research Program.

\section{DISCLOSURE}

The authors report no disclosures relevant to the manuscript. Go to Neurology.org for full disclosures.

Received May 20, 2016. Accepted in final form October 10, 2016.

\section{REFERENCES}

1. Langlois JA, Rutland-Brown W, Wald MM. The epidemiology and impact of traumatic brain injury: a brief overview. J Head Trauma Rehabil 2006;21:375-378.

2. Bolouri H, Zetterberg H. Animal models for concussion: molecular and cognitive assessments-relevance to sport and military concussions. In: Kobeissy FH, editor. Brain Neurotrauma: Molecular, Neuropsychological, and Rehabilitation Aspects. Boca Raton: Frontiers in Neuroengineering, 2015.

3. Makdissi M. Sports related concussion: management in general practice. Aust Fam Physician 2010;39:12-17.

4. Baugh CM, Kroshus E, Stamm JM, Daneshvar DH, Pepin MJ, Meehan WP III. Clinical practices in collegiate concussion management. Am J Sports Med 2016;44: 1391-1399.

5. Strathmann FG, Schulte S, Goerl K, Petron DJ. Bloodbased biomarkers for traumatic brain injury: evaluation of research approaches, available methods and potential utility from the clinician and clinical laboratory perspectives. Clin Biochem 2014;47:876-888.

6. McKee AC, Cantu RC, Nowinski CJ, et al. Chronic traumatic encephalopathy in athletes: progressive tauopathy after repetitive head injury. J Neuropathol Exp Neurol 2009;68:709-735.

7. Stein TD, Alvarez VE, McKee AC. Chronic traumatic encephalopathy: a spectrum of neuropathological changes following repetitive brain trauma in athletes and military personnel. Alzheimers Res Ther 2014;6:4.

8. Gabbita SP, Scheff SW, Menard RM, Roberts K, Fugaccia I, Zemlan FP. Cleaved-tau: a biomarker of neuronal damage after traumatic brain injury. J Neurotrauma 2005;22: 83-94.

9. Anderson JM, Hampton DW, Patani R, et al. Abnormally phosphorylated tau is associated with neuronal and axonal loss in experimental autoimmune encephalomyelitis and multiple sclerosis. Brain 2008;131:1736-1748.

10. Franz G, Beer R, Kampfl A, et al. Amyloid beta 1-42 and tau in cerebrospinal fluid after severe traumatic brain injury. Neurology 2003;60:1457-1461.

11. Ost M, Nylen K, Csajbok L, et al. Initial CSF total tau correlates with 1-year outcome in patients with traumatic brain injury. Neurology 2006;67:1600-1604.

12. Neselius S, Zetterberg H, Blennow K, et al. Olympic boxing is associated with elevated levels of the neuronal protein tau in plasma. Brain Inj 2013;27:425-433.

13. Shahim P, Tegner Y, Wilson DH, et al. Blood biomarkers for brain injury in concussed professional ice hockey players. JAMA Neurol 2014;71:684-692.

14. McCrory P, Meeuwisse W, Johnston K, et al. Consensus statement on concussion in sport: the 3rd international conference on concussion in sport held in Zurich, November 2008. J Athletic Train 2009;44:434-448.

15. Corrigan JD, Bogner J. Initial reliability and validity of the Ohio State University TBI identification method. J Head Trauma Rehabil 2007;22:318-329.

16. Collins MW, Iverson GL, Lovell MR, McKeag DB, Norwig J, Maroon J. On-field predictors of neuropsychological and symptom deficit following sports-related concussion. Clin J Sport Med 2003;13:222-229.

17. Iverson GL, Lovell MR, Collins MW. Interpreting change on ImPACT following sport concussion. Clin Neuropsychologist 2003;17:460-467.

18. Guskiewicz K. Postural stability assessment following concussion: one piece of the puzzle. Clin J Sport Med 2001; 11:182-189.

19. Rissin DM, Fournier DR, Piech T, et al. Simultaneous detection of single molecules and singulated ensembles of molecules enables immunoassays with broad dynamic range. Anal Chem 2011;83:2279-2285.

20. Shahim P, Mattsson N, Macy EM, et al. Serum visininlike protein- 1 in concussed professional ice hockey players. Brain Inj 2015;29:872-876.

21. Rasmussen P, Brassard P, Adser H, et al. Evidence for a release of brain-derived neurotrophic factor from the brain during exercise. Exp Physiol 2009;94:1062-1069.

22. Stocchero CMA, Oses JP, Cunha GS, et al. Serum S100B level increases after running but not cycling exercise. Appl Physiol Nutr Metab 2013;39:340-344.

23. Ding Q, Vaynman S, Souda P, Whitelegge JP, Gomez-Pinilla F. Exercise affects energy metabolism and neural plasticity-related proteins in the hippocampus as revealed by proteomic analysis. Eur J Neurosci 2006;24:12651276.

24. Knaepen K, Goekint M, Heyman EM, Meeusen R. Neuroplasticity: exercise-induced response of peripheral brain-derived neurotrophic factor: a systematic review of experimental studies in human subjects. Sports Med 2010;40:765-801.

25. Sharma HS, Cervos-Navarro J, Dey PK. Increased bloodbrain barrier permeability following acute short-term swimming exercise in conscious normotensive young rats. Neurosci Res 1991;10:211-221.

26. Saur L, Baptista PPA, de Senna PN, et al. Physical exercise increases GFAP expression and induces morphological changes in hippocampal astrocytes. Brain Struct Funct 2014;219:293-302.

27. Shahim P, Arnell P, Kvarnstrom A, et al. Cerebrospinal fluid markers of central nervous system injury in decompression 
illness: a case-controlled pilot study. Diving Hyperb Med 2015;45:240-243.

28. McCulloch KL, Goldman S, Lowe L, et al. Development of clinical recommendations for progressive return to activity after military mild traumatic brain injury: guidance for rehabilitation providers. J Head Trauma Rehabil 2015;30:56-67.

29. Kerr ZY, Snook EM, Lynall RC, et al. Concussionrelated protocols and preparticipation assessments used for incoming student-athletes in national collegiate athletic association member institutions. J Athl Train 2015;50:1174-1181.

30. Oldenburg C, Lundin A, Edman G, Nygren-de Boussard C, Bartfai A. Cognitive reserve and persistent postconcussion symptoms-a prospective mild traumatic brain injury (mTBI) cohort study. Brain Inj 2016;30:146-155.

31. Shitaka Y, Tran HT, Bennett RE, et al. Repetitive closedskull traumatic brain injury in mice causes persistent multifocal axonal injury and microglial reactivity. J Neuropathol Exp Neurol 2011;70:551-567.

32. Mouzon BC, Bachmeier C, Ferro A, et al. Chronic neuropathological and neurobehavioral changes in a repetitive mild traumatic brain injury model. Ann Neurol 2014;75: 241-254.

33. Cheng JS, Craft R, Yu GQ, et al. Tau reduction diminishes spatial learning and memory deficits after mild repetitive traumatic brain injury in mice. PLoS One 2014;9: e115765.

34. Petraglia AL, Plog BA, Dayawansa S, et al. The pathophysiology underlying repetitive mild traumatic brain injury in a novel mouse model of chronic traumatic encephalopathy. Surg Neurol Int 2014;5:184.

35. Barrio JR, Small GW, Wong KP, et al. In vivo characterization of chronic traumatic encephalopathy using [F-18] FDDNP PET brain imaging. Proc Natl Acad Sci USA 2015;112:E2039-E2047.

\section{Subspecialty Alerts by E-mail!}

Customize your online journal experience by signing up for e-mail alerts related to your subspecialty or area of interest. Access this free service by visiting Neurology.org/site/subscriptions/etoc.xhtml or click on the "E-mail Alerts" link on the home page. An extensive list of subspecialties, methods, and study design choices will be available for you to choose from—allowing you priority alerts to cutting-edge research in your field!

\section{Visit the Neurology ${ }^{\circledR}$ Website at Neurology.org}

- Enhanced navigation format

- Increased search capability

- Highlighted articles

- Detailed podcast descriptions

- RSS Feeds of current issue and podcasts

- Personal folders for articles and searches

- Mobile device download link

- AAN Web page links

- Links to Neurology Now ${ }^{\circledR}$, Neurology Today ${ }^{\circledR}$, and Continuum ${ }^{\circledR}$

- Resident \& Fellow subsite

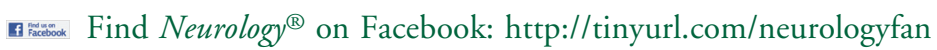

twitter Follow Neurology ${ }^{\circledR}$ on Twitter: https://twitter.com/GreenJournal 


\section{Neurology}

\section{Acute plasma tau relates to prolonged return to play after concussion Jessica Gill, Kian Merchant-Borna, Andreas Jeromin, et al.}

Neurology 2017;88;595-602 Published Online before print January 6, 2017

DOI 10.1212/WNL.0000000000003587

This information is current as of January 6, 2017

\begin{tabular}{|c|c|}
\hline $\begin{array}{l}\text { Updated Information \& } \\
\text { Services }\end{array}$ & $\begin{array}{l}\text { including high resolution figures, can be found at: } \\
\text { http://n.neurology.org/content/88/6/595.full }\end{array}$ \\
\hline Supplementary Material & $\begin{array}{l}\text { Supplementary material can be found at: } \\
\text { http://n.neurology.org/content/suppl/2017/01/06/WNL. } 0000000000003 \\
\text { 587.DC1 }\end{array}$ \\
\hline References & $\begin{array}{l}\text { This article cites } 34 \text { articles, } 3 \text { of which you can access for free at: } \\
\text { http://n.neurology.org/content/88/6/595. full\#ref-list-1 }\end{array}$ \\
\hline Citations & $\begin{array}{l}\text { This article has been cited by } 7 \text { HighWire-hosted articles: } \\
\text { http://n.neurology.org/content/88/6/595.full\#\#otherarticles }\end{array}$ \\
\hline Subspecialty Collections & $\begin{array}{l}\text { This article, along with others on similar topics, appears in the } \\
\text { following collection(s): } \\
\text { All Clinical Neurology } \\
\text { http://n.neurology.org/cgi/collection/all_clinical_neurology }\end{array}$ \\
\hline Permissions \& Licensing & $\begin{array}{l}\text { Information about reproducing this article in parts (figures,tables) or in } \\
\text { its entirety can be found online at: } \\
\text { http://www.neurology.org/about/about_the_journal\#permissions }\end{array}$ \\
\hline Reprints & $\begin{array}{l}\text { Information about ordering reprints can be found online: } \\
\text { http://n.neurology.org/subscribers/advertise }\end{array}$ \\
\hline
\end{tabular}

Neurology ${ }^{\circledR}$ is the official journal of the American Academy of Neurology. Published continuously since 1951, it is now a weekly with 48 issues per year. Copyright Copyright (C) 2017 The Author(s). Published by Wolters Kluwer Health, Inc. on behalf of the American Academy of Neurology. All rights reserved. Print ISSN: 0028-3878. Online ISSN: 1526-632X.

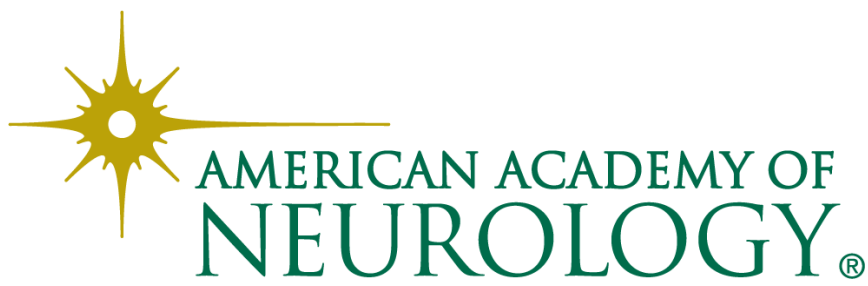

